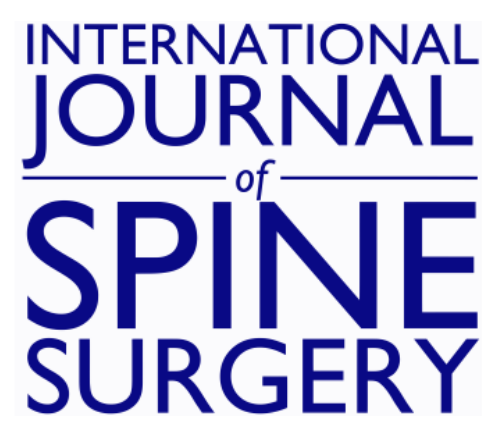

\title{
Endoscopic Trans-iliac Approach to L5-S1 Disc and Foramen - A Report on Clinical Experience
}

Said G Osman, Sandeep Sherlekar, Atif Malik, Charles Winters, PK Grewal, Malini Narayanan and Nigussie Gemechu

Int J Spine Surg 2014, 8 ()

doi: https://doi.org/10.14444/1020

http://ijssurgery.com/content/8/20

This information is current as of April 26, 2023.

Email Alerts Receive free email-alerts when new articles cite this article. Sign up at:

http://ijssurgery.com/alerts

The International Journal of Spine Surgery

2397 Waterbury Circle, Suite 1,

Aurora, IL 60504, Phone: +1-630-375-1432 


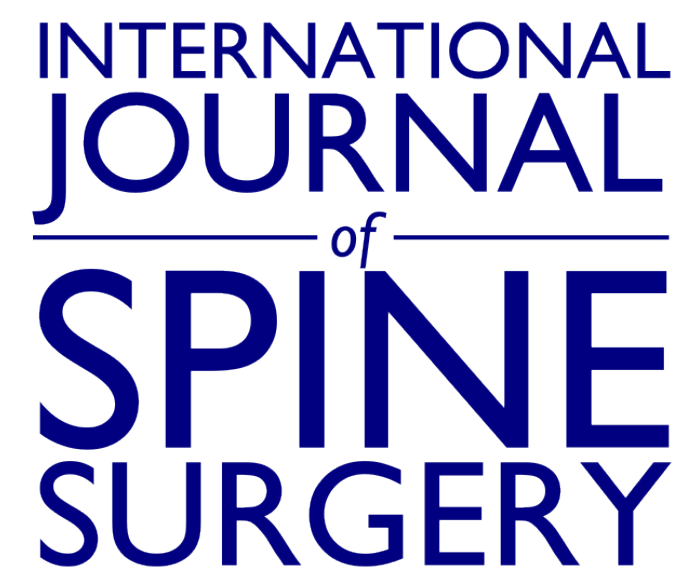

This article generously published free of charge by the International Society for the Advancement of Spine Surgery.

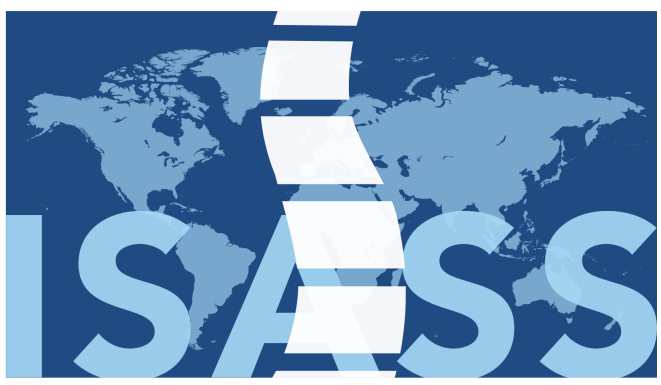

INTERNATIONAL SOCIETY for the ADVANCEMENT of SPINE SURGERY 


\section{Endoscopic Trans-iliac Approach to L5-S1 Disc and Foramen - A Report on Clinical Experience}

Said G Osman, MD, FAAOS, FRCSEd (ortho), Sandeep Sherlekar, MD, Atif Malik, MD, Charles Winters, MD, PK Grewal, MD, Malini Narayanan, MS, MD, Nigussie Gemechu, MS

American Spine, Germantown, MD

\section{Abstract}

\section{Background}

The lumbosacral junction is a difficult area for spine surgery because of the complex anatomy. In the era of minimally invasive spine surgery, the presence of the iliac wing has, at the level of lumbosacral junction, created a major obstacle in the paths of two of the major approaches, namely, the direct lateral and percutaneous posterolateral endoscopic approaches. A trans-iliac cadaver study published by the senior author and coworkers in 1997, suggested the possibility of an alternative approach to the lumbosacral junction.

\section{Purpose}

To determine the feasibility of percutaneous, endoscopic trans-iliac approach to the L5-S1 disc and foramen

\section{Study Design}

Prospective case series study.

\section{Materials and Methods}

15 consecutive patients undergoing the transiliac approach to L5-S1 disc and foramen were included in the study. Pre- and postoperative visual analogue scale (VAS); Oswestry Disability Index (ODI); and intra-operative blood loss and operative time, were obtained for the study. Preoperative MRI or CT scan was used to determine the need for trans-iliac access. The procedure was performed with the patient in prone position and under monitored sedation for decompression. Endotracheal anesthesia was used for fusion cases. The transiliac access was established with a cannulated drill or core drill through the iliac wing. Once the trans-iliac window had been created, the rest of the procedure proceeded as for percutaneous endoscopic transforaminal decompression and fusion. 


\section{Results}

15 patients ( 9 male and 6 female) participated in the study. The VAS for back and leg pain significantly improved in all patients. The ODI dropped by more than $50 \%$. There was minimal blood loss, and transient post-operative dysesthesia in 2 cases which resolved after 3 weeks.

\section{Conclusion}

Endoscopic trans-iliac approach to the L5-S1 disc and foramen is feasible and safe. Decompression can be performed safely via trans-iliac access with minimal blood loss, and in a short operative time.

keywords: Percutaneous, Endoscopic, trans-iliac, trans-foraminal, Iliac crest

Volume 8 Article 20 - Endoscopic \& Percutaneous Special Issue doi: 10.14444/1020

\section{Introduction}

In the effort to minimize surgical trauma, and the resulting morbidity at lumbosacral junction, several minimally invasive approaches have been introduced in recent years. Examples of these approaches include, but not limited to, minimally invasive transforaminal lumbar interbody fusion (TLIF), ${ }^{1,2}$ minimally invasive anterior lumbar interbody fusion (ALIF), ${ }^{3,4}$ AxiaLIF, ${ }^{5,6}$ MIS interlaminar approach, ${ }^{7}$ endoscopic interlaminar approach, ${ }^{8,9}$ and percutaneous endoscopic lumbar transforaminal (PELD) approach. While all these options have resolved some of the problems related to the traditional approaches, they have also introduced their own sets of access-related problems. Direct lateral lumbar interbody fusion (DLIF), currently being practiced widely for minimally invasive lumbar fusions, ${ }^{10,11,12}$ cannot access the L5-S1 level because of the iliac bone blocking the access. While the proponents of the DLIF approach are generally happy with the technique, the rather high prevalence of injury to the lumbar plexus, albeit generally mild, ${ }^{13,14}$ especially at the L4-5 disc level where the degenerative motion-segment diseases is more prevalent, may discourage others from embracing the technique. The AxiaLIF or presacral approach, while indeed minimizing the accessrelated trauma of the traditional surgery, tracks in vicinity of the bowel and major vessels with the potential of serious complications. ${ }^{15}$ Access with this approach is limited to the L4-5 and L5-S1 levels and there is concern about fusion of L4-5 in hyperlordosis. ${ }^{16}$

The senior author and his co-workers performed a cadaver study to determine the feasibility of the trans-iliac approach, in late 1990s and this work was published in 1997. ${ }^{17}$ The background to that study was the inaccessibility of the L5-S1 disc and foramen for trans-foraminal endoscopic instrumentation in situations where the disc is seated deep in the pelvis. The cadaver study revealed that the trans-iliac access channel traversed gluteus maximus and gluteus medius in four out of five specimens. The superior gluteal neurovascular bundle was about 4.8 centimeters caudal to the transiliac window. There were no injuries to the sacro-iliac joints, ilio-lumbar ligaments or facet joints (Figure 1). 


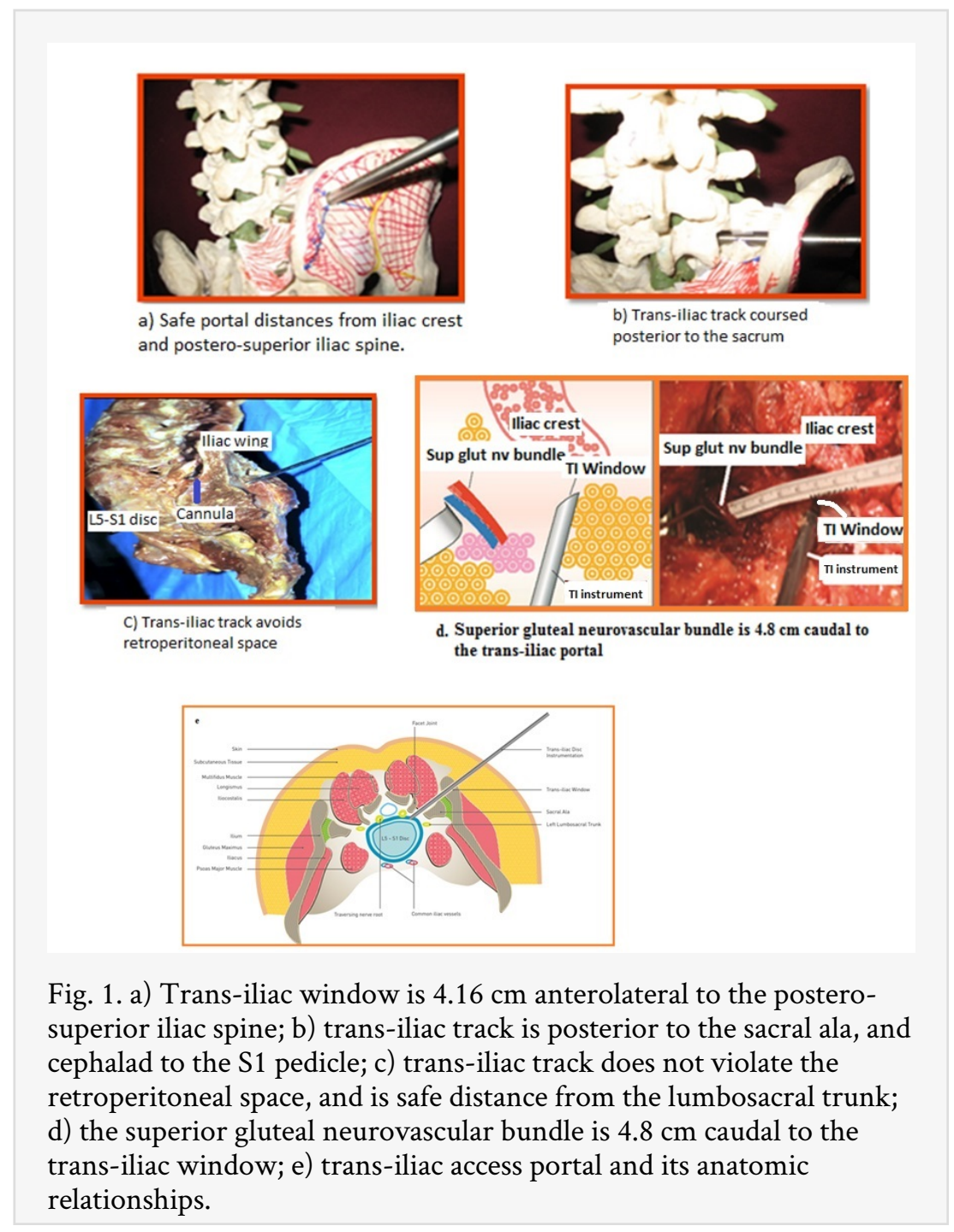

With the advances in technology which makes it possible to perform endoscopic foraminoplasty; endoscopic excision of the more central disc pathology; and percutaneous interbody fusions, the authors recognize the utility of this approach at the lumbosacral joint. Based on the findings of the cadaver study, the senior author has been performing this procedure mainly on patients with deep seated L5-S1 discs since 1996.

\section{Materials and Methods}

This is a report on 18 consecutive cases that had trans-iliac approach performed for access to the L5-S1 disc and foramen. The transiliac access was necessary in these patients because of deep-seated L5-S1 to facilitate transforaminal foraminoplasty, and for percutaneous transforaminal interbody fusion. preoperative ODI, VAS score were completed preoperatively and at the last follow-up. 
Preoperative X-rays and MRIs were studied. Using the axial view of the L5-S1 on the MRI, a line is drawn from the target lesion on the disc to exit the skin posterolaterally as shown on Figure 2. Measurement of the portal site from the midline, and the angle of instrumentation relative to the sagittal plane of the spine were measured and recorded as preoperative planning.

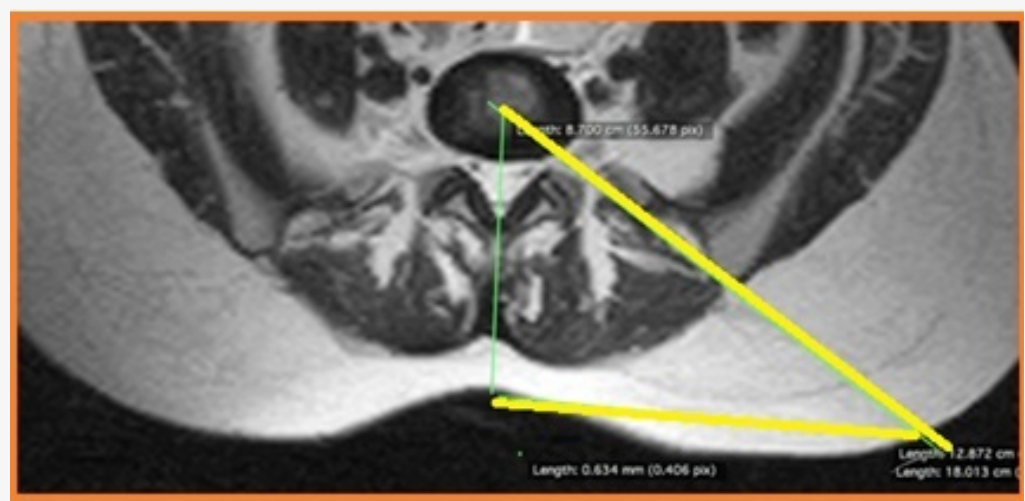

Fig. 2.

Light sedation and local anesthetic infiltration of the access track was adequate for most patients. Neuromonitor was used to record MEPs and EMGs. Anti-embolic stockings and SCD devices are routinely used to prevent deep venous thrombosis. The patient is placed in prone position on radiolucent operating table on Kambin or Wilson frame. After sterile preparation, transparent drape is used to permit visualization of foot pedals with the fluoroscope in lateral position. Under antero-posterior fluoroscopic guidance, the midline of the spine was marked on the skin, and while visualizing with Ferguson projection the disc line was marked on the skin (Figure 3).

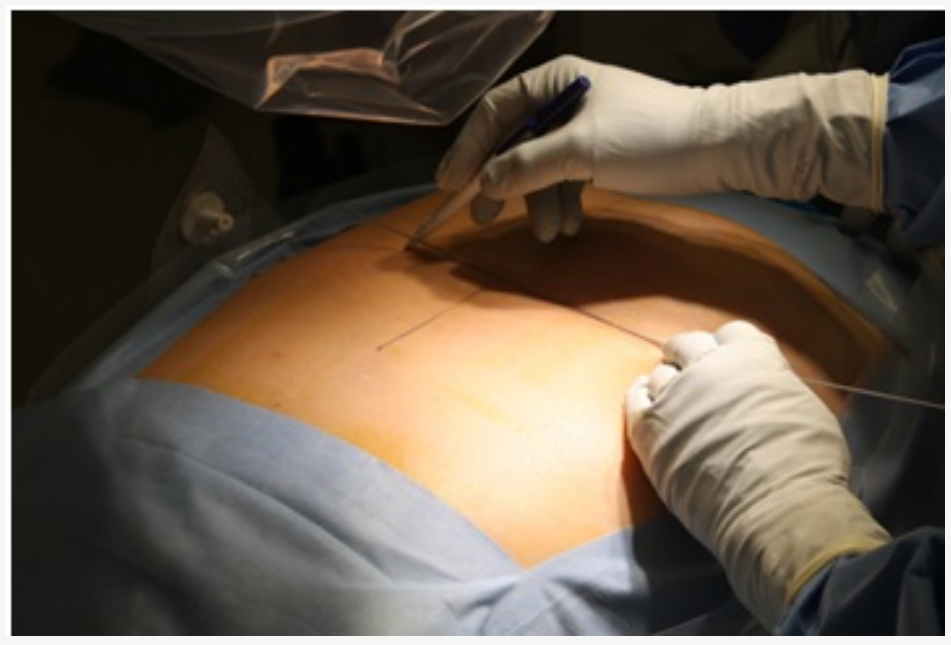

Fig. 3.

The portal site, the access track, and the periosteum of the iliac wing were infiltrated with $0.5 \%$ bupivacaine with epinephrine. A stab incision was made with a \# 11 blade.

Guidewire, mounted on a power drill, was inserted through the portal in the 
predetermined angle and advanced to the ilium. The wire was driven through the medial cortex of the ilium and position was checked fluoroscopically in Ferguson and lateral positions (Figure 4).
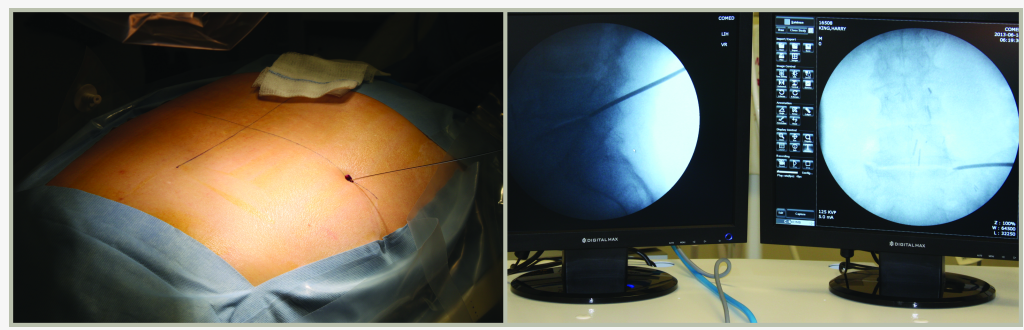

Fig. 4.

To ensure the correct trajectory of the track the wire is then advanced while monitoring its progress in Ferguson and lateral projections. A guidewire subtending wide angle to the sagittal plane of the spine may be close to the spine on Ferguson projection, while on the lateral projection it lies far posterior to the disc or facet joint. If the wire is close to the disc on the lateral projection and far from the disc on Ferguson projection, the wire needs to be re-inserted at an angle closer to the coronal plane. After the right trajectory had been established, and the guidewire had been inserted through the iliac wing, cannulated dilator is inserted over the guide wire up to the lateral wall of the ilium. The access cannula is inserted over the dilator, and the dilators are removed. Using an $8 \mathrm{~mm}$ automated reamer, or manual trephine, inserted over the guidewire, the iliac window is created under biplanar fluoroscopic control. Once the trans-iliac window has been created, routine foraminal and disc instrumentation with guidewire, obturator and access cannula is performed (Figure 5).

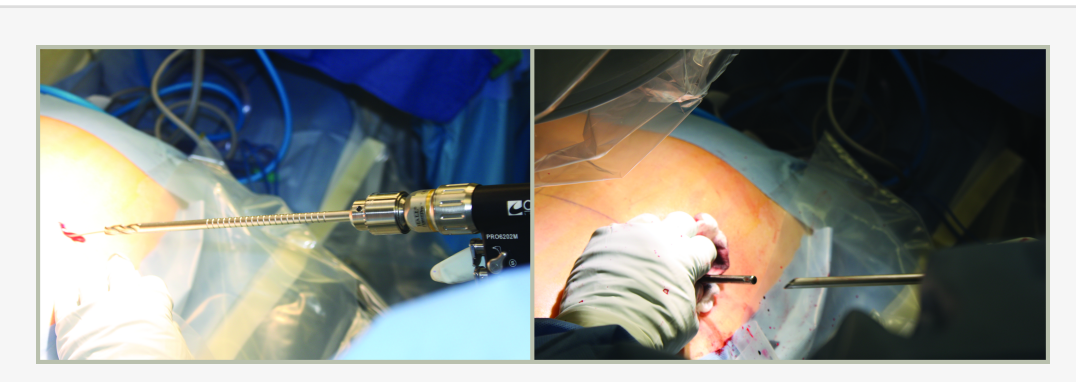

Fig. 5.

After inserting the spinal needle into the disc, chromodiscography is performed to determine the partho-anatomy of the disc. ${ }^{18}$ Instrumentation was then carried out with the obturator and a cannula. The subsequent steps were determined by the pathology. If there was a ruptured disc, the cannula was partially docked into the disc and the operating arthroscope was introduced. Removal of disc fragments was carried out using graspers (Figure 6). 


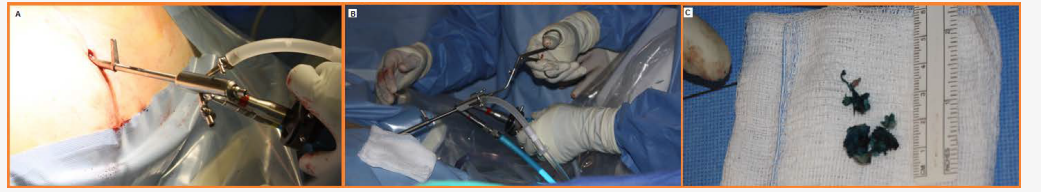

Fig. 6. A: Arthroscope in place; B: using grasping forceps to remove disc; C: disc fragments removed.

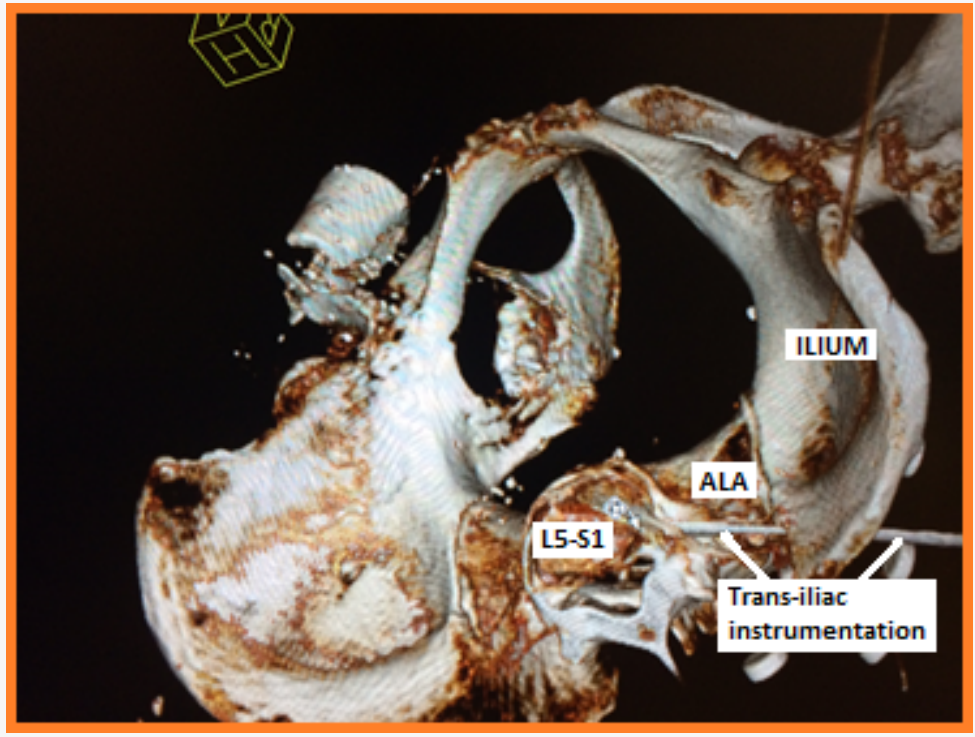

Fig. 7. A 3D CT scan of the lumboscacral junction showing a trans-iliac guidewire tracking posterior to the sacral ala, into the posterolateral L5-S1 disc transforaminally.

If the procedure was for fusion of a degenerated motion-segment with collapsed disc and subarticular stenosis, preliminary percutaneous pedicle screw instrumentation was performed. Distraction was carried out to open up the foraminal canal and displace the exiting nerve root cephalad. Trans-iliac access window was established as discussed above. Instrumentation of the disc was performed with spinal needle, guidewire, obturator and a threaded cannula. The cannula was held against the disc annulus and the wire and obturator removed. A $5 \mathrm{~mm}$ trephine is used to perform annulotomy at the level of the lateral recess to decompress the traversing nerve. The threaded cannula was docked into the disc and discectomy commenced. End-plate preparation was carried out with expandable reamers. The adequacy of the end-plate preparation is confirmed endoscopically. Allograft bone chips mixed with bone marrow aspirate is then packed anteriorly into the disc space. Further grafting is performed with an expandable interbody device.

Intra-operative data collected include operating room time (entry to exit time from the operating room), operating time (OT), access time (AT) (incision to the start of cure time, and from end of cure time to wound closure), cure time (CT) is operating minus access time (OT-AT), and estimated blood loss. 


\section{Results}

Fifteen patients ( 9 male and 6 female) were included in the study and underwent endoscopic transforaminal decompression. Mean age was 45 years (range 27 - 61 years). Average post-operative follow-up was 12.5 months (range 2 -18.5 months).

Mean preoperative leg pain on VAS scale was 8.7 (range 6-10); and mean postoperative leg pain was 2.9 (range 0-9) (Figure 8 ). The change is statistically significant $(\mathrm{p}<0.001)$.

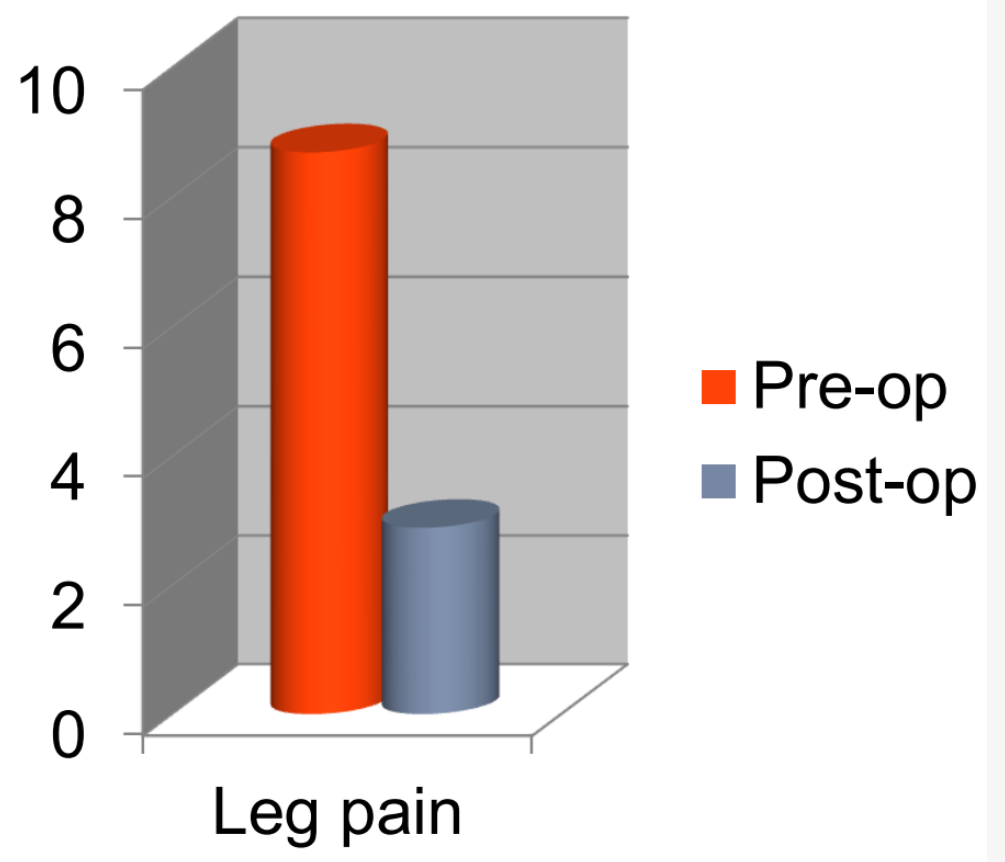

Fig. 8. Pre- and postoperative leg pain.

Back pain dropped from 7.1 preoperatively to 3.6, (Figure 9) also statistically significant $(\mathrm{p}<0.0005)$. 


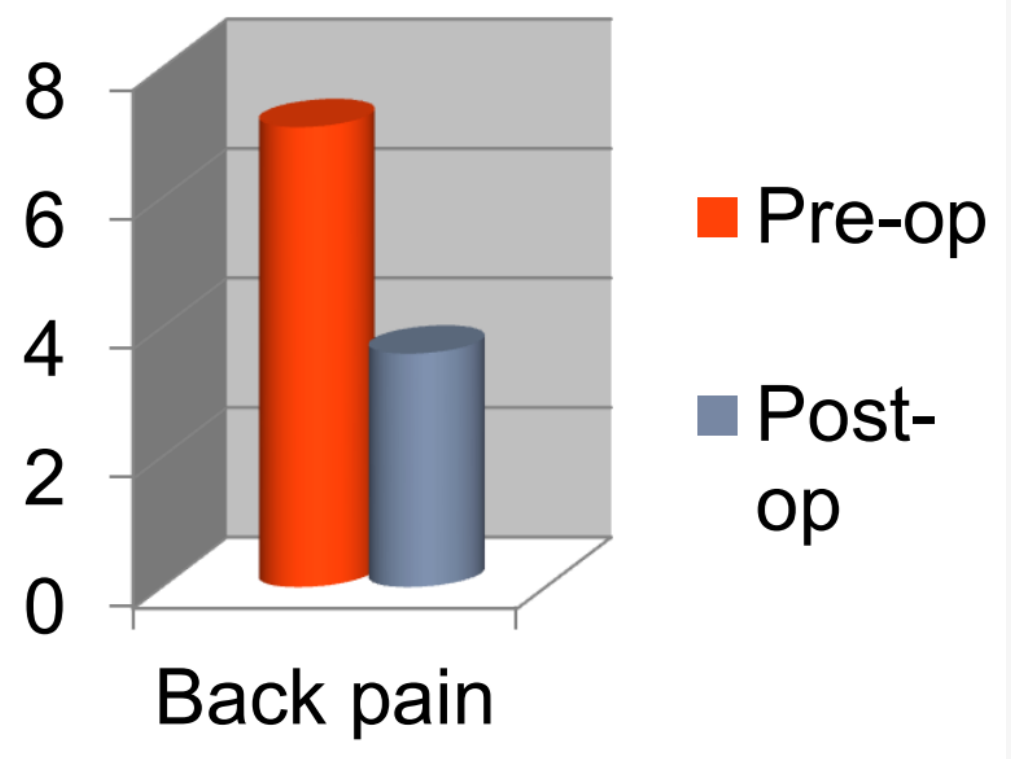

Fig. 9. Pre- and postoperative low back pain.

Oswestry Disability Index (ODI) dropped from preoperative 32.8 to post-operative 16.7 $(\mathrm{p}<0.0001)$ (Figure 10).

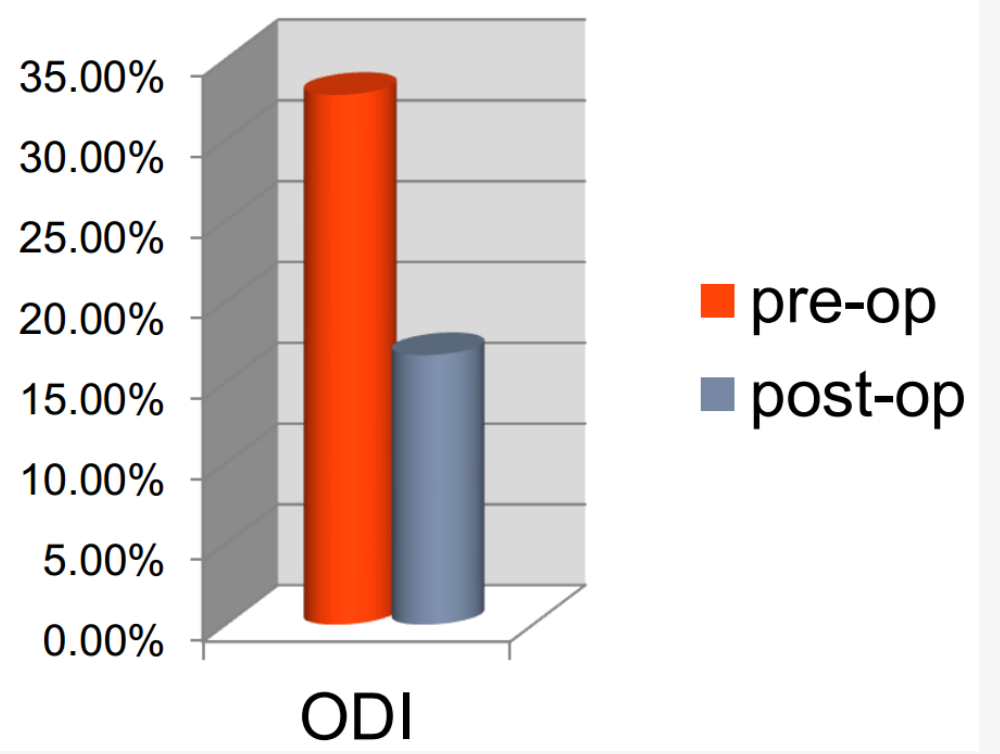

Fig. 10. Pre- and postoperative ODI.

\section{Discussion}

The lumbosacral junction poses a challenge for the spine surgeon who aims to perform minimally invasive surgery at the L5-S1 level. The options include, but not limited to, interlaminar approach7,8,9, percutaneous transforaminal decompression, ${ }^{18,19,20}$ anterior 
approach and presacral approach. Percutaneous, transforaminal oblique interbody fusion has recently been introduced - the technique involves interbody instrumentation through the foramen without excision of the facet joint. ${ }^{21,22}$ While the percutaneous, transforaminal, endoscopic approach avoids traversing the spinal canal, in situations where the L5-S1 is deeply seated in the pelvis, supra-iliac approach may be impossible, or risks injury to the exiting L5 nerve root. Even in situations where the pelvic anatomy is normal, a more centrally located lesion at L5-S1 level such as central disc herniation, or facet hypertrophy with foraminal stenosis, will require a far lateral portal to access the lesions, hence, the need for trans-iliac approach. When the original cadaver study was carried out ${ }^{17}$ the main concern was risk of injury to vital structures in the trans-iliac access. The study clearly demonstrated there were no neural or vascular structures in the neighborhood of the transiliac access channel. Significantly, there was minimal risk of penetration into the pelvic cavity or retroperitoneal space. The intra-foraminal relation to the access channel was same as described by the senior author in a prior study. ${ }^{23}$ Embryologically, the ilium derives from the same mesenchymal tissue as the paraspinal muscles which are traversed by the more cephalad transforaminal endoscopic procedures, hence, it is not surprising that the track is posterior to the posterior wall of the pelvic cavity.

The preoperative MRI showing axial slice through the L5-S1 disc and revealing the posterior wall of the back, including the skin is utilized to plan the portal site and angle of percutaneous instrumentation. This will reduce the risk of making portals at inappropriate distances from midline, and angle of instrumentation. With experience, targeting the posterolateral corner of the disc through trans-iliac approach will become easy. The authors have also experienced few cases with very high iliac wing, necessitating transiliac instrumentation of L4-5 disc and foramen.

\section{Conclusion}

Endoscopic trans-iliac approach to the L5-S1 disc and foramen is feasible and safe. Decompression can be performed safely via trans-iliac access with minimal blood loss, and in a short operating time. The limitation of the direct lateral approach imposed by the iliac bone is overcome. The risks of trans-canal, retroperitoneal and presacral approaches are avoided. A randomized controlled trial of much larger sample of patients, followed up for a longer duration is required to validate some the data published in this article.

\section{References}

1. Kim JS, Jung B, Lee SH. Instrumented Minimally Invasive spinal-Transforaminal Lumbar Interbody Fusion (MIS-TLIF); Minimum 5-years Follow-up With Clinical and Radiologic Outcomes. J Spinal Disord Tech. 2012 Sep 28.

2. Habib A, Smith ZA, Lawton CD, Fessler RG. Minimally invasive transforaminal lumbar interbody fusion: a perspective on current evidence and clinical knowledge. Minim Invasive Surg. 2012;2012:657342

3. Lee SH, Choi WG, Lim SR, Kang HY, Shin SW. Minimally invasive anterior lumbar interbody fusion followed by percutaneous pedicle screw fixation for isthmic spondylolisthesis. Spine J. 4(6):644-9.2004 Nov-Dec; 
4. Kim JS, Choi WG, Lee SH. Minimally invasive anterior lumbar interbody fusion followed by percutaneous pedicle screw fixation for isthmic spondylolisthesis: minimum 5-year follow-up. Spine J. 10(5):404-9.2010 May;

5. Gerszten PC, Tobler WD, Nasca RJ. Retrospective analysis of L5-S1 axial lumbar interbody fusion (AxiaLIF): a comparison with and without the use of recombinant human bone morphogenetic protein-2. Spine J. 2011 Nov;11(11):1027-32.

6. Gerszten PC, Tobler W, Raley TJ, Miller LE, Block JE, Nasca RJ. Axial presacral lumbar interbody fusion and percutaneous posterior fixation for stabilization of lumbosacral isthmic spondylolisthesis. J Spinal Disord Tech. 2012 Apr;25(2)

7. Casal-Moro R, Castro-Menéndez M, Hernández-Blanco M, Bravo-Ricoy JA, JorgeBarreiro FJ. Long-term outcome after microendoscopic diskectomy for lumbar disk herniation: a prospective clinical study with a 5-year follow-up. Neurosurgery: 68(6):1568-75, 2011 Jun;

8. Dezawa A, Sairyo K. New minimally invasive discectomy technique through the interlaminar space using a percutaneous endoscope. Asian J Endosc Surg: 4(2):94-82011 May.

9. Choi G, Prada N, Modi HN, Vasavada NB, Kim JS, Lee SH. Percutaneous endoscopic lumbar herniectomy for high-grade down-migrated L4-L5 disc through an L5-S1 interlaminar approach: a technical note. Minim Invasive Neurosurg. 53(3):147-52. 2010 Jun.

10. Arnold PM, Anderson KK, McGuire RA Jr. The lateral transpsoas approach to the lumbar and thoracic spine: A review. Surg Neurol Int. 2012;3(Suppl 3):S198-215.

11. Kepler CK, Sharma AK, Huang RC, Meredith DS, Girardi FP, Cammisa FP Jr, Sama AA. Indirect foraminal decompression after lateral transpsoas interbody fusion. J Neurosurg Spine. 2012 Apr;16(4):329-33

12. Berjano P, Balsano M, Buric J, Petruzzi M, Lamartina C. Direct lateral access lumbar and thoracolumbar fusion: preliminary results. Eur Spine J. 2012 May;21 Suppl $1:$ S37-42

13. Knight RQ, Schwaegler P, Hanscom D, Roh J. Direct lateral lumbar interbody fusion for degenerative conditions: early complication profile. J Spinal Disord Tech: 22(1):34-7; 2009 Feb.

14. Banagan K, Gelb D, Poelstra K, Ludwig S. Anatomic mapping of lumbar nerve roots during a direct lateral transpsoas approach to the spine: a cadaveric study. Spine: 36(11):E687-91 2011 May 15.

15. Lindley EM, McCullough MA, Burger EL, Brown CW, Patel VV. Complications of axial lumbar interbody fusion. J Neurosurg Spine. 15(3):273-9, 2011 Sep.

16. Marchi L, Oliveira L, Coutinho E, Pimenta L. Results and complications after 2-level axial lumbar interbody fusion with a minimum 2-year follow-up. J Neurosurg Spine. 17(3):187-92: 2012 Sep.

17. Osman SG, et al. Endoscopic Transiliac Approach to L5-S1 Disc and Foramen - A Cadaver Study. Spine: 22, \#11:1259, 1997.

18. Yeung AT, Gore S. In vivo Endoscopic Visualization of Patho-anatomy in Symptomatic Degenerative Conditions of the Lumbar Spine II: Intradiscal, Foraminal, and Central Canal Decompression. Surg Technol Int. XXI: 299-319; Dec 2011.

19. Yeung AT, Yeung CA. Advances in endoscopic disc and spine surgery: foraminal approach. Surg Technol Int. 11:255-63; 2003. 
20. Kambin P, O'Brien E, Zhou L, Schaffer JL. Arthroscopic microdiscectomy and selective fragmentectomy. Clin Orthop Relat Res. 1998 Feb;(347):150-67

21. Osman SG. Endoscopic Transforaminal Decompression, Interbody Fusion and Percutaneous Pedicle Screw Implantation. International Journal of Spine Surgery. Volume 6, Issue 1, Pages 157-166, December 2012

22. Katzell, J. A less invasive Tranforaminal Appoach to Lumbar Interbody Fusion. ISMISS/SICOT International 31st Course for Percutaneous Endoscopic Spinal Surgery and Complementary Minimally Invasive Techniques, January 2013.

23. Osman SG, Marsolais EB. Posterolateral Arthroscopic Discectomies of the Thoracic and Lumbar Spine. Clinical Ortho. \& Related Research: 304:122-129, 1994.

\section{Disclosures}

The authors have declared no financial disclosures.

Copyright (C) 2014 ISASS - International Society for the Advancement of Spine Surgery. To see more or order reprints or permissions, see http://ijssurgery.com. 